\title{
Effects of Neuromedin $S$ on the proliferation of splenic lymphocytes and the cytokine secretion by pulmonary alveolar macrophages in pigs in vitro
}

\author{
R. Lin ${ }^{1}$, Q. Wang ${ }^{1}$, B. Qi, Y. Huang, G. Yang \\ University Key Laboratory for Integrated Chinese Traditional and Western Veterinary Medicine and Animal \\ Healthcare, College of Animal Science, Fujian Agriculture and Forestry University, $15^{\text {th }}$ Shang-xia-dian Road, \\ Fuzhou, Fujian Province 350002, PR China
}

\begin{abstract}
Neuromedin S (NMS), a 36-amino acid neuropeptide, has been found to be involved in the regulation of the endocrine activity. It has been also detected in immune tissues in mammals, what suggests that NMS may play an important role in the regulation of immune response. The aim of this study was to demonstrate the presence of NMS receptor 1 (NMU1R) and effect of NMS in pig splenic lymphocytes (SPLs) and pulmonary alveolar macrophages (PAMs). The presence of NMU1R in pig SPLs and PAMs was respectively confirmed by reverse transcription-polymerase chain reaction (RT-PCR), western blot analysis and immunocytochemical methods. Furthermore, SPL proliferation was analyzed using the 3-(4,5)-dimethyl-thiahiazo-(-2-yl)-3,5-di-phenytetrazoliumromide (MTT) method. Additionally, the secretion of interleukin (IL)-1 $\beta$, IL- 6 and tumor necrosis factor- $\alpha$ (TNF- $\alpha$ ) in PAMs was all measured by enzyme-linked immunosorbent assay (ELISA) kits. In the present study, the results of RT-PCR and western blot analysis revealed that NMU1R mRNA and protein were both expressed in pig SPLs and PAMs, and the immunocytochemical investigations further revealed that the positive signal of NMU1R immunoreactivity was observed in plasma membranes of both SPLs and PAMs. In the in vitro study, we found that at concentrations of 0.001-1000 nM NMS alone or combined with lipopolysaccharide or phytohemagglutinin significantly increased SPL proliferation. Application of ELISA method showed that NMS could induce the secretion of the pro-inflammatory cytokines IL- $1 \beta$, IL- 6 and TNF- $\alpha$ in PAMs. These results suggest that NMS can act as a potently positive pro-inflammatory factor and immunomodulatory agent that affects the immune response of immune cells by combining with its receptor NMU1R.
\end{abstract}

Key words: NMS, pig, SPLs, proliferation, PAMs, cytokines

Correspondence to: G. Yang, e-mail: YGH15659731438@163.com

${ }^{1}$ The first two authors contributed equally to this study 


\section{Introduction}

Neuromedin S (NMS), a novel containing 36-amino acid neuropeptide found in the rat brain, was identified as the second endogenous ligand for two orphan G-protein-coupled receptors (FM-3/GPR66/NMU1R and FM-4/TGR-1/NMU2R) in rats after Neuromedin $U$ (NMU) using a reverse-pharmacological technique (Mori et al. 2005). This peptide was named NMS because of its specific expression in the suprachissmatic nucleus (SCN) of the rat hypothalamus (Mori et al. 2005). Mori et al. (2008) and Malendowicz et al. (2012) have revealed that NMS and NMU share the same C-terminal seven amino acid residues and combine with the common two receptors (NMU1R and NMU2R), and that they can be involved in several similar physiological functions, such as the regulation of reproduction (Vigo et al. 2007, Yang et al. 2009, 2010), feeding behaviors (Howard et al. 2000, Ida et al. 2005, Shousha et al. 2006, Peier et al. 2009), energy homeostasis (Nakazato et al. 2000, Hanada et al. 2003, Nakahara et al. 2004), circadian rhythms (Mori et al. 2005, Sakamoto et al. 2007) and stress responses (Hanada et al. 2001). These studies were mostly performed in rats, humans and batrachia; very few available reports deal with pigs, especially with pig cells.

Previous studies (Hedrick et al. 2000, Moriyama et al. 2006a) have reported that NMU1R is expressed specifically in the various immune cell types; NMU1R mRNA was found in mast cells and eosinophils of mice (Moriyama et al. 2005, 2006b). It is worth mentioning that NMU1R has been detected in a wide range of peripheral tissues, including the lung, intestine, testis, pancreas, uterus and kidney, which are markedly different from the distribution of NMU2R in animal tissues (Howard et al. 2000, Mori et al. 2005, Atsuchi et al. 2010). Recent research demonstrated that NMU has a potential pro-inflammatory role and that mRNA encoding NMU1R, identified by ${ }^{125}$ I-labeled NNU was high-affinity saturable binding sites in a mouse Th2 cell line. Furthermore, this study was revealed that NMU can affect immune cells, and can increase the secretion of interleukins (ILs)-4, 5, 6, 10, and 13 (Moriyama et al. 2006b, Johnson et al. 2012). Hence, we speculated whether NMS might be involved in the immune response and induced cytokine secretion in pig immune cells.

To date, the expression of NMU1R mRNA in immune cells is still unknown in pig. Therefore, the aim of this study was to demonstrate the presence of NMU1R mRNA and NMU1R protein in pig splenic lymphocytes (SPLs) and pulmonary alveolar macrophages (PAMs) by reverse transcription-polymerase chain reaction (RT-PCR), immunocytochemistry and western blot analysis, respectively. In this paper, we further investigated the effects of NMS on SPL proliferation alone or in combination with lipopolysaccharide (LPS) or phytohemagglutinin (PHA) using the 3-(4,5)-dimethylthiahiazo-(-2-yl)-3,5-diphenytetrazoliumromide (MTT) method in viro. Additionally, we studied the effect of NMS on the secretion of pro-inflammatory cytokines, including interleukin (IL)-1 $\beta$, IL- 6 and tumor necrosis factor- $\alpha$ (TNF- $\alpha)$ in pig PAMs using an enzyme-linked immunosorbent assay (ELISA) kit.

\section{Materials and Methods}

\section{Animals and reagents}

The study was performed on Normal Landrace pigs (aged 1 month, body weight $10 \pm 0.25 \mathrm{~kg}$ ) obtained from a farm in Putian of Fujian Province of China. All the pigs were individually housed in $1.5 \mathrm{~m} \times 2.0 \mathrm{~m}$ slatted-floored pens equipped with self-feeders and nipple drinkers; furthermore, all the animals were fed and vaccinated according to the breeding standards of Chinese Local pigs and the National Research Council (NRC), and the procedures in this experiment were undertaken according to the guidelines of the local Ethics Commission in Fujian Province of China. Pigs were euthanized and dissected in order to obtain the spleen and lungs on the day of the experiment, and then SPLs and PAMs were isolated, cultured and processed. NMS peptide (ANASPEC International Inc, USA) was dissolved in RPMI 1640 at concentrations of $0.001,0.01,0.1,1,10,100$ and $1000 \mathrm{nM}$ and stored at $-20^{\circ} \mathrm{C}$ before the use.

\section{Isolation and culture of splenic lymphocytes}

All subsequent procedures were performed under sterile conditions. After series of washes with $70 \%$ ethanol and 0.1 M phosphate-buffered saline (PBS) $(\mathrm{PH}=7.4)$, the spleen was rapidly harvested and placed in a small culture dish. A cell suspension was then obtained by squeezing tissue through a cell strainer with a bent syringe needle attached to a 5-ml syringe plunger. The splenocytes were dissociated from the tissue capsule by gently pressing the tissue through a sterile nytox mesh. Cells were then centrifuged at $1000 \mathrm{~g}$ for $10 \mathrm{~min}$ at $4^{\circ} \mathrm{C}$, erythrocytes were lysed with red blood cell lysis buffer for $10 \mathrm{~min}$, and the supernatant was then discarded and washed twice with 0.1 M PBS. For monocyte depletion, spleen cells were cultured in modified RPMI 1640 (Hyclone, USA) complete medium containing $10 \%$ heat-inac- 
tivated fetal bovine serum (HIFBS) (Hyclone, USA) and $1 \%$ penicillin-streptomycin solution (Hyclone, USA), and were incubated at $37^{\circ} \mathrm{C}$ in a humidified $5 \%$ $\mathrm{CO}_{2}$ atmosphere for $1 \mathrm{~h}$ to allow the cells to attach to the flask bed. Cell numbers and viability were determined by counting the number of cells excluding trypan blue $(0.4 \%)$ using a hemocytometer. The final cell concentration of each well was adjusted to $1 \times 10^{5}$ cells $\mathrm{ml}^{-1}$. Cell suspensions with a $95 \%$ or higher viability rate were used for the experimental assays.

\section{Isolation and culture of pulmonary alveolar macrophages}

Bronchoalveolar lavages and collections were performed as previously described (Yao et al. 2011). The harvested cells were added to red blood cell lysis buffer and centrifuged at $1000 \mathrm{~g}$ at $4^{\circ} \mathrm{C}$ for $10 \mathrm{~min}$, and the supernatant was discarded. PAMs were washed with RPMI 1640 medium and then cultured in modified RPMI 1640 complete medium supplemented with $10 \%$ HIFBS and $1 \%$ penicillin-streptomycin solution. Cell viability and concentration were evaluated by trypan blue exclusion in a hemocytometer. Only those cells with a viability rate above $95 \%$ were used for the assays.

\section{RT-PCR}

After incubation for $48 \mathrm{~h}$ at $37^{\circ} \mathrm{C}$ with $5 \% \mathrm{CO}_{2}$ under the non-treated condition, the cells were harvested and stored at $-80^{\circ} \mathrm{C}$ until RNA extraction was performed. Total RNA was isolated from the SPLs or PAMs using TRIzol reagent (Invitrogen, USA) according to the manufacturer's protocol. Total RNA was then treated with RNase-free DNase I (Beijing Solarbio Bioscience Technology Co. Ltd., China), and the RNA concentration and quality were determined using an Ultra-Micro spectrophotometer (NanoDrop 2000, Gene Company Limited Co. Ltd.,). Then, approximately $1 \mu \mathrm{g}^{\mathrm{l}} \mathrm{l}^{-1}$ of total RNA was used as a template for first-strand cDNA synthesis using GoScript $^{\mathrm{TM}}$ Reverse Transcription System (Promega, USA), according to the manufacturer's protocol. The following cycling parameters were applied: $95^{\circ} \mathrm{C}$ for $10 \mathrm{~min}$ and 32 cycles of amplification $\left(95^{\circ} \mathrm{C}\right.$ for $30 \mathrm{~s}$, $58^{\circ} \mathrm{C}$ for $40 \mathrm{~s}$ and at $72^{\circ} \mathrm{C}$ for $30 \mathrm{~s}$ ), and a final extension step at $72^{\circ} \mathrm{C}$ for $5 \mathrm{~min}$. The intermediate PCR fragments were amplified in a $25 \mu$ reaction system containing $2 \mu \mathrm{l}$ of template cDNA, $0.2 \mu \mathrm{M}$ each sense and antisense primers, $9.5 \mu \mathrm{l}$ of $\mathrm{ddH}_{2} \mathrm{O}$ and $12.5 \mu \mathrm{l}$ GoTaq $^{\circledR}$ Green Master Mix (Promega, USA). The specific PCR primers for NMU1R were designed us- ing Primer Premier 5.0 and were based on the conserved region of the pig NMU1R gene. Primer sequences were as follows: sense 5'-GCACGCCTACCAACTACTAC-3', antisense 5'-ATGGGCAGGCAGAAGAAGAGCAG-3'. RT-PCR was performed in PCR system $\mathrm{C} 1000^{\mathrm{TM}}$ Thermal cycler (BIO-RAD, USA) and repeated at least two times. Finally, amplified products were resolved by $1.2 \%$ agarose gel electrophoresis at 100 Volage for $20 \mathrm{~min}$. Gel was stained with ethidium bromide and viewed under UV transilluminator Gel Doc XR imaging system (BIO-RAD, USA).

\section{Western blot analysis}

The SPLs and PAMs were lysed using RIPA lysis buffer (Beijing Solarbio Technology Co., Ltd., China) supplemented with a mixture of PMSF and 30 min lysis on ice, and then the cell lytic supernatants were obtained by centrifugation at $12000 \mathrm{~g}$ at $4^{\circ} \mathrm{C}$ for $10 \mathrm{~min}$. The total cell lysate was separated on a $10 \%$ sodium dodecyl sulfate-polyacrylamide gel (SDS-PAGE) using electrophoresis and transferred onto a polyvinylidene difluoride membranes (PVDF, Beyotime Institute of Biotechnology, China). The membrane was blocked overnight at $4^{\circ} \mathrm{C}$ in $5 \%$ non-fat dry milk, and then incubated for $8 \mathrm{~h}$ at $4^{\circ} \mathrm{C}$ with different primary antibodies (Anti-NMU1R, SC-135159, Santa Cruz Biotechnology, Inc., 1:800; anti- $\beta$-actin, AP0060, Bioworld Technology, Inc., 1:8000). After washing in tris-buffered saline (TBST) (Beijing ComWin Biotech Co., Ltd., China) three times, the membranes were incubated with secondary antibody for $2 \mathrm{~h}$ at room temperature. The signal was detected by BeyoECL Plus (Beyotime Institute of Biotechnology, China). Chemiluminescence signal was then transferred on an X-OMAT BT Film (Xiamen Carestream Health, Inc., China).

\section{Immunocytochemistry}

The isolated SPLs were adjusted to a final concentration of $5 \times 10^{6}$ cells ml ${ }^{-1}$ in $0.1 \mathrm{M}$ PBS. SPL suspensions were seeded onto microscope slides and placed at room temperature for $10 \mathrm{~min}$. The supernatant was carefully discarded. PAMs at a concentration of $5 \times 10^{6}$ cells ml ${ }^{-1}$ were seeded onto microscope slides in six-well plates and incubated at $37^{\circ} \mathrm{C}$ for $48 \mathrm{~h}$ to allow the cells to attach to the microscope slides, and the supernatant fluid was then carefully discarded. The slides were air-dried at $25^{\circ} \mathrm{C}$ for $30 \mathrm{~min}$ after the microscope slides were washed twice in 0.1 M PBS. Slides were processed for immunocytochemistry using a previously validated method (Yang et al. 2010). 
Table 1. The experimental scheme of SPL proliferation in vitro.

\begin{tabular}{ccccccc}
\hline Group & $\begin{array}{c}\text { Cell suspension } \\
(\mu \mathrm{l})\end{array}$ & $\begin{array}{c}\text { NMS } \\
(\mu \mathrm{l})\end{array}$ & $\begin{array}{c}\text { PHA } \\
(\mu \mathrm{l})\end{array}$ & $\begin{array}{c}\text { LPS } \\
(\mu \mathrm{l})\end{array}$ & $\begin{array}{c}\text { RPMI 1640 } \\
(\mu \mathrm{l})\end{array}$ & $\begin{array}{c}\text { Total volume } \\
(\mu \mathrm{l})\end{array}$ \\
\hline NMS & 100 & 50 & 0 & 0 & 50 & 200 \\
NMS+PHA & 100 & 50 & 50 & 0 & 0 & 200 \\
NMS+LPS & 100 & 50 & 0 & 50 & 0 & 200 \\
PHA & 100 & 0 & 50 & 50 & 50 & 200 \\
LPS & 100 & 0 & 0 & 0 & 100 & 200 \\
Blank & 100 & 0 & 0 & 0 & 200 \\
\hline
\end{tabular}

NMS, PHA $\left(80 \mu \mathrm{g} \mathrm{ml}^{-1}\right)$ and LPS $\left(20 \mu \mathrm{g} \mathrm{m}^{-1}\right)$ were diluted with RPMI 1640 complete medium; NMS, neuromedin S; SPL, splenic lymphocyte; PHA, phytohemagglutinin; LPS, lipopolysaccharide.

Table 2. The sample application method for cytokine detection.

\begin{tabular}{cccccc}
\hline Group & $\begin{array}{c}\text { Cell suspension } \\
(\mu \mathrm{l})\end{array}$ & $\begin{array}{c}\text { NMS } \\
(\mu \mathrm{l})\end{array}$ & $\begin{array}{c}\text { LPS } \\
(\mu \mathrm{l})\end{array}$ & $\begin{array}{c}\text { RPMI 1640 } \\
(\mu \mathrm{l})\end{array}$ & $\begin{array}{c}\text { Total volume } \\
(\mu \mathrm{l})\end{array}$ \\
\hline NMS & 1000 & 10 & 0 & 10 & 1020 \\
NMS+LPS & 1000 & 10 & 10 & 0 & 1020 \\
LPS & 1000 & 0 & 10 & 10 & 1020 \\
Blank & 1000 & 0 & 0 & 20 & 1020 \\
\hline
\end{tabular}

PAMs were treated with various concentrations of NMS $(0.01,0.1,1,10,100$ and $1000 \mathrm{nM})$ alone or in combination with LPS $\left(20 \mu \mathrm{g} \mathrm{ml}^{-1}\right)$ for $12 \mathrm{~h}$ at $37^{\circ} \mathrm{C}$ with $5 \% \mathrm{CO}_{2}$ in incubator.

Immunocytochemistry analyses were performed using a streptavidin-biotin complex (SABC) kit (Fuzhou Maixin Biological Technology Co., Ltd., China). The SPLs and PAMs on the slides were fixed with $4 \%$ paraformaldehyde in $0.1 \mathrm{M}$ PBS for $10 \mathrm{~min}$ and then washed with $0.1 \mathrm{M}$ PBS three times. One in every five cell slides was incubated with the primary antibody raised against NMU1R (anti-NMU1R: SC-135159, Santa Cruz Biotechnology, Inc. diluted $1: 400$ in $0.1 \mathrm{M} \mathrm{PBS}$ ) and with the appropriated secondary antibody (biotinylated goat-anti rabbit $\mathrm{IgG})$. Then, the cell sliders were incubated with streptavidin-biotin complex (SABC) reagent at $37^{\circ} \mathrm{C}$ for $30 \mathrm{~min}$. Then, the bound antibodies underwent 5 min of exposure to a freshly prepared chromogen solution containing $0.02 \% \quad 3,3$ '-diaminobenzidine (DAB) (Wuhan Boster Biological Technology Co. Ltd., Wuhan, China) in distilled water, which resulted in the production of a deep brown color. The reaction was stopped by washing the slides three times in distilled water. The cells were counterstained with hematoxylin. In the negative control, the primary antibody was replaced with a normal rabbit serum. Finally, the slides were dehydrated in ethanol, cleared in xylene, and mounted with glass cover slips. Images were acquired using bright-field microscopy (Olympus BH-2, Olympus Corporation, China).

\section{SPL proliferation assays}

SPL proliferation was determined using the 3-(4,5)-dimethylthiahiazo(-z-yl)-3,5-di-phenytetrazoliumromide (MTT, Amresco, USA) method (Solis-Maldonado et al. 2003). Briefly, $1 \times 10^{6}$ cells $\mathrm{ml}^{-1}$ SPLs were harvested and added in a 96-well microplate supplemented with different concentrations of NMS (0.001, 0.01, 0.1, 1, 10, 100 and 1000 $\mathrm{nM}$ ) and $80 \mu \mathrm{g} \mathrm{ml}^{-1}$ PHA (Promega, USA) or $20 \mu \mathrm{g}$ $\mathrm{ml}^{-1}$ LPS (Promega, USA). Additionally, the cells were cultured with LPS/PHA alone or treated with various concentrations of NMS alone. The experimental design is shown in Table 1. After incubation for 44 $\mathrm{h}$ at $37^{\circ} \mathrm{C}$ with $5 \% \mathrm{CO}_{2}, 0.5 \mathrm{mg} \mathrm{ml}^{-1}$ MTT was added to each well, and the samples were incubated for additional $4 \mathrm{~h}$. The optical densities resulting from dissolved formazan crystals were determined in a multimode microplate reader (Infinite M200, Tecan, Austria) at $570 \mathrm{~nm}$. Six duplicates for each experimental condition were performed to minimize the effect of experimental errors, and all the experiments had been done for more than six times. 


\section{Cytokine measurements}

PAM suspensions were adjusted to a final concentration of $1 \times 10^{6}$ cell ml ${ }^{-1}$ in each six-well plate, and the cells were treated with various concentrations of NMS $(0.01,0.1,1,10,100$ and $1000 \mathrm{nM})$ or in combination with LPS $\left(20 \mu \mathrm{g} \mathrm{ml}^{-1}\right)$ for $12 \mathrm{~h}$ at $37^{\circ} \mathrm{C}$ with $5 \%$ $\mathrm{CO}_{2}$. The experimental design of the cytokine secretion of PAMs is shown in Table 2. The cell supernatants were collected and stored at $-20^{\circ} \mathrm{C}$ until analysis. IL-1 $1 \beta$, IL- 6 and TNF- $\alpha$ levels were measured with the use of ELISA kit (Quantikine, R\&D systems, USA) in accordance with the manufacturer's instructions. Briefly, ELISA 96-well microplate were coated with antibodies specific for pig and incubated overnight at $4^{\circ} \mathrm{C}$. Then, each well was aspirated and washed with wash buffer, followed by blocking with $1 \%$ Bovine albumin (BSA) (Sigma, USA) to each well for $2 \mathrm{~h}$ at $37^{\circ} \mathrm{C}$. Afterwards, the cell supernatants or standards were added in the plate for $2 \mathrm{~h}$ at $37^{\circ} \mathrm{C}$, and biotinylated antibodies, specific for pig cytokines, were subsequently added in the plate and incubated for $1 \mathrm{~h}$ at $37^{\circ} \mathrm{C}$. Then, HRP-conjugated streptavidin solution was added and incubated for $60 \mathrm{~min}$. In each stage, plates were rinsed three or five times in PBS. Subsequently, substrate solution including 1:1 mixture of color reagent $\mathrm{A}\left(\mathrm{H}_{2} \mathrm{O}_{2}\right)$ and color reagent $\mathrm{B}$ (tetramethylbenzidine) was added, and then the enzymatic reaction was stopped with the stop solution. Finally, the cytokine levels were measured and assayed using a microliter ELISA reader (Beckman, USA). Six duplicates for each experimental condition were performed to decrease the effects of experimental errors, and all the experiments had been done for more than six times.

\section{Statistical analysis}

The data are presented as the mean \pm SEM. Statistical analysis was performed by one-way analysis of variance (ANOVA) in IBM SPSS Statistics 19.0 software. Differences were considered significant at $\mathrm{p}<0.05$. Differences were considered highly significant at $\mathrm{p}<0.01$.

\section{Results}

\section{NMU1R mRNA expression in pig SPLs and PAMs}

The expression of NMU1R mRNA in SPLs and PAMs of normal pigs was detected by RT-PCR. Single 457-bp band representing NMU1R mRNA was analyzed by electrophoresis of SPL mRNAs (Fig. 1A), and a single fragment of the same size was found in PAMs (Fig. 1B).

\section{Expression of NMU1R protein in pig SPLs and PAMs}

As shown in Fig. 2, western blot analysis revealed that NMU1R protein was expressed in pig SPLs and PAMs. The further research confirmed the presence of the positive signal of NMU1R immunoreactivity in the plasma membranes of both SPLs and PAMs (Fig. 3).

\section{Effect of NMS on pig SPL proliferation}

As shown in Fig. 4, dynamic changes in SPL proliferation were observed at various concentrations of NMS (0.001, 0.01, 0.1, 1, 10, 100 and $1000 \mathrm{nM})$. Compared with the blank group, 0.001-1 nM NMS highly significantly stimulated the SPL proliferation $(p<0.01)$, and the effect of 10-1000 nM NMS also significantly increased SPL proliferation $(\mathrm{p}<0.05)$. But, the highest value was observed for the $1 \mathrm{nM}$ NMS group (Fig. 4A).

Moreover, the NMS+PHA/LPS group showed markedly promoted SPL proliferation $(\mathrm{p}<0.01)$ (Fig. 4A, Fig. 4C, respectively). Interestingly, different concentrations of NMS in combination with PHA or LPS amplified SPL proliferation $(\mathrm{p}<0.01)$ compared with the blank group, and the $A_{570}$ values in the NMS+PHA groups and NMS+LPS groups were higher than those of the NMS alone groups when compared with the results obtained in the blank group or in the LPS/PHA group (Fig. 4A, Fig. 4B, Fig. 4C, Fig. 4D, respectively). However, LPS did not amplify the proliferation of SPLs at the concentration of 1000 nM NMS compared with that obtained in the LPS group (Fig. 4B). Additionally, the highest values of $\mathrm{A}_{570}$ were observed in the $0.01 \mathrm{nM}$ NMS+LPS group (Fig. 4A, Fig. 4B, respectively) and the $0.1 \mathrm{nM}$ NMS+PHA group (Fig. 4C, Fig. 4D, respectively).

\section{Effects of NMS on IL-1 $\beta$, IL-6 and TNF- $\alpha$ secretion in pig PAMs}

The effects of NMS on the secretion of IL-1 $\beta$, IL- 6 and TNF- $\alpha$ in PAMs were shown in Fig. 5. The secretion of IL-1 $1 \beta$, IL- 6 and TNF- $\alpha$ was dramatically up-regulated by LPS treatment $(\mathrm{p}<0.05)$. There was no significant difference in IL-1 $\beta$ secretion $(p>0.05)$ between the 1-1000 nM NMS group and the blank 


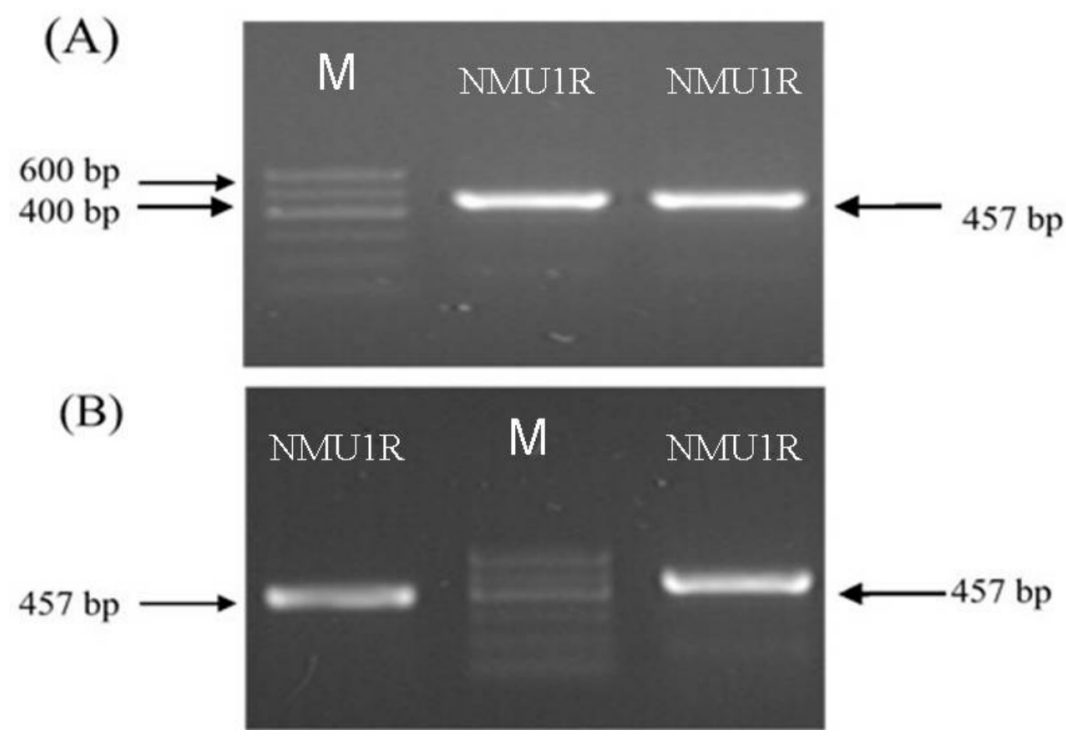

Fig. 1. NMU1R expression in pig SPLs (A) and PAMs (B). M, marker; NMU1R, two duplications for pig NMU1R amplifications (457 bp); SPLs, splenic lymphocytes; PAMs, pulmonary alveolar macrophages.

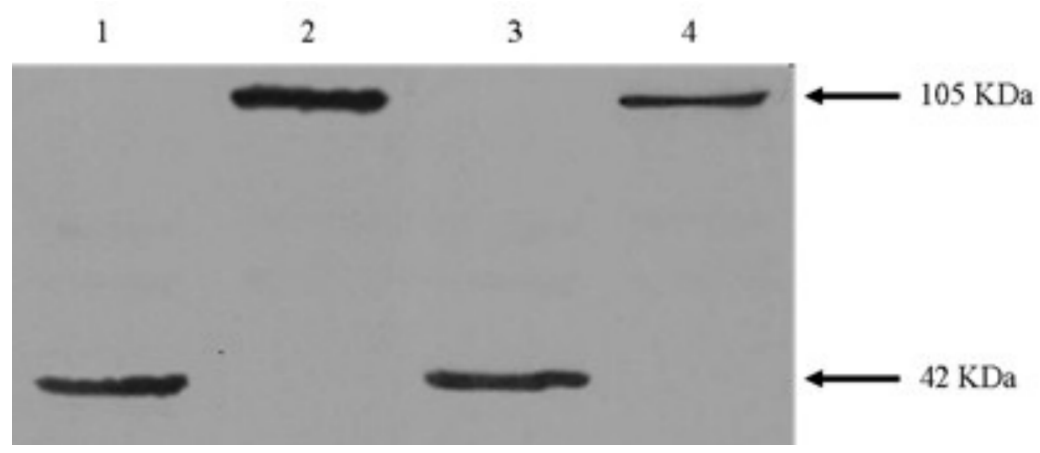

Fig. 2. The expression of NMU1R protein in pig SPLs and PAMs without NMS treatment revealed by western blot analysis. 1, the expression of $\beta$-actin in pig SPLs; 2 , the expression of NMU1R in pig SPLs; 3 , the expression of $\beta$-actin in pig PAMs; 4 , the expression of NMU1R in pig PAMs.

group (Fig. 5A). However, IL-1 $\beta$ secretion was significantly up-regulated by 0.01 and $0.1 \mathrm{nM}$ NMS $(\mathrm{p}<0.05$ compared with the blank group) in the NMS treatment alone group, whereas, IL-6 and TNF- $\alpha$ secretion levels were significantly up-regulated by 10 and 100 nM NMS ( $<<0.05$ compared with the blank group) (Fig. 5B, Fig. 5C, respectively).

In the combined group, IL-1 $\beta$ secretion was dramatically enhanced by 0.01-1 nM NMS + LPS ( $\mathrm{p}<0.05$ compared with the blank group and the LPS group) and $100 \mathrm{nM}$ NMS+LPS $(\mathrm{p}<0.05$ compared with the blank group). However, 1-100 nM NMS+LPS significantly increased the secretion of IL-6 and TNF- $\alpha$ $(\mathrm{p}<0.05$, compared with the blank group and the LPS group). Interestingly, IL-1 $\beta$ secretion reached its maximum level at the concentration of $0.1 \mathrm{nM}$ NMS and LPS, and that of IL- 6 and TNF- $\alpha$ reached the maximum level under the induction of $1 \mathrm{nM}$ NMS combined with LPS in PAMs.

\section{Discussion}

Earlier publications have revealed that NMS mRNA is highly expressed in the suprachiasmatic nucleus (SCN) of the brain, spleen and testis (Mori et al. 2005), and NMU1R mRNA has been also detected in mast cells and eosinophils (Moriyama et al. 2005, 2006b). These findings suggest that NMS and NMU1R may represent an interesting system associated with pig immune cells. In the present study, the RT-PCR investigations showed that NMU1R mRNA was expressed in pig SPLs and PAMs. The result of western blot revealed only one single band that could be used to confirm the specific binding of the antibody (anti-NMU1R) against its antigen which was expressed in the pig SPLs and PAMs. Previous studies have shown that NMU1R belongs to the G-protein coupled receptor (GPCR) family and is localized in the plasma membrane (Fujii et al. 2000, Wang et al. 


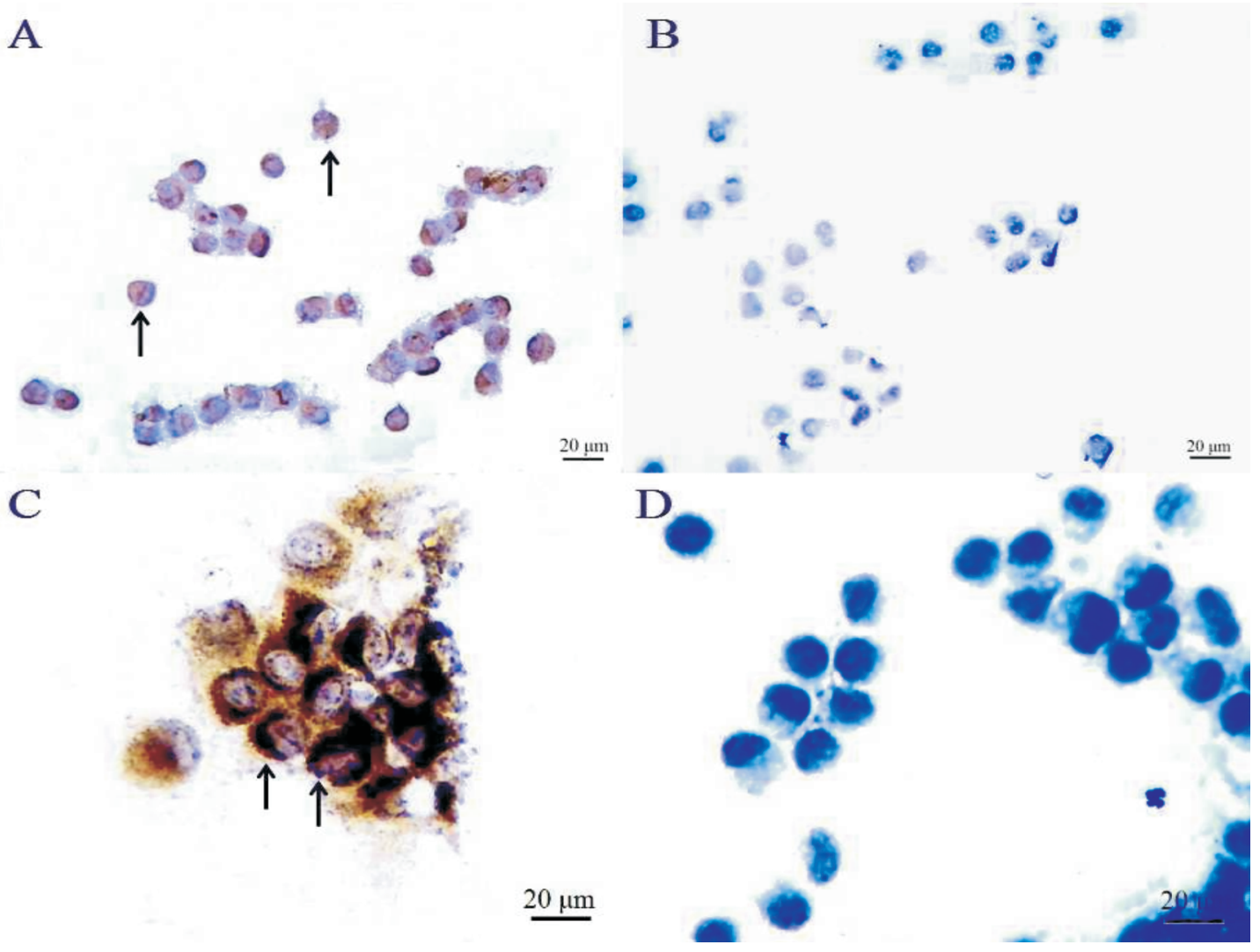

Fig. 3. NMU1R immunoreactivity in pig SPLs (A and B) and PAMs (C and D). Strong immunoreactivity of NMU1R (brown staining) was observed in the plasma membranes of both SPLs (A) and PAMs (C); the nuclei were counterstained with hematoxylin (B, D). Negative blank samples did not show any signal. SPLs, splenic lymphocytes; PAMs, pulmonary alveolar macrophages. The arrows point to the typical and significant cells. Scale bars in A, B, C and D $=20 \mu \mathrm{m}$.

2011). In the present research, we have also provided further evidence for the distribution of NMU1R in the plasma membranes of both two types of cells in pigs by immunocytochemical method. Thus, these molecular and morphology results suggest that NMS can be involved in regulating the immune response of immune cells, but whether SPLs and PAMs have the capacity to produce sufficient NMS to affect the NMS-NMU1R system in an autocrine-like, paracrine-like, or endocrine manner is unknown, and this mechanism needs further study. It would be also interesting to investigate the effect of NMS combined with NMU1R on immune cells in pigs.

Here, the effect of different concentration of NMS on SPL proliferation showed that NMS significantly increased the proliferation of SPLs in vitro. This result suggests that $0.001-1 \mathrm{nM}$ NMS has a positive effect on cellular immunity. In the combined group, SPL proliferation was respectively also increased by $0.001-1000 \mathrm{nM}$ NMS in combination with LPS or PHA. Thus, we speculate that NMS can act as an immunomodulator playing the positive effect on specific immunity over a certain range of concentra- tions, and may be involved in the modulatory pathways associated with the cellular immunity in pigs through NMU1R mediation.

Additionally, we examined the effect of NMS on pro-inflammatory cytokine secretion in pig PAMs. A certain concentration of NMS significantly improved the secretion of IL- $1 \beta$, IL- 6 and TNF- $\alpha$, and the certain concentrations of NMS in combination with LPS had a synergistic effect on cytokine secretion by PAMs. These data suggest that NMS can promote the secretion of IL-1 $\beta$, IL- 6 and TNF- $\alpha$ in pig PAMs. Previous studies have shown that IL-1 $\beta$, IL- 6 and TNF- $\alpha$ was potent mediators of pro-inflammatory mechanisms associated with macrophage stimulation (Kelley 1990). Therefore, all these data further suggest that NMS may serve as pro-inflammatory mediator and is involved in inflammatory reaction in pig immune cells. Our findings indicate that NMS may act as a pro-inflammatory mediator which could provide initial evidence for the NMS is involved in the cellular immune response. Further studies on the detailed mechanism of NMS in the immune response are necessary. 
(A) $\quad$ NMS

NMS+LPS

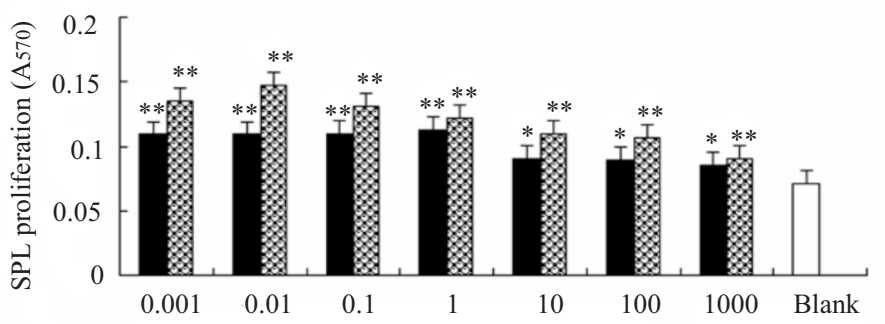

(B)

- NMS

6. NMS+LPS

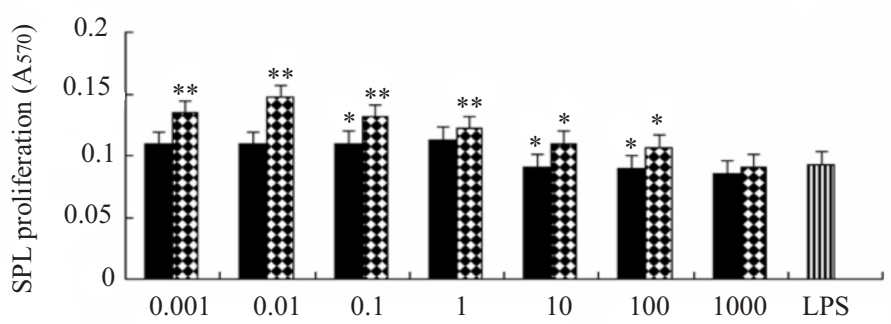

(C)

- NMS

영 $\mathrm{NMS}+\mathrm{PHA}$

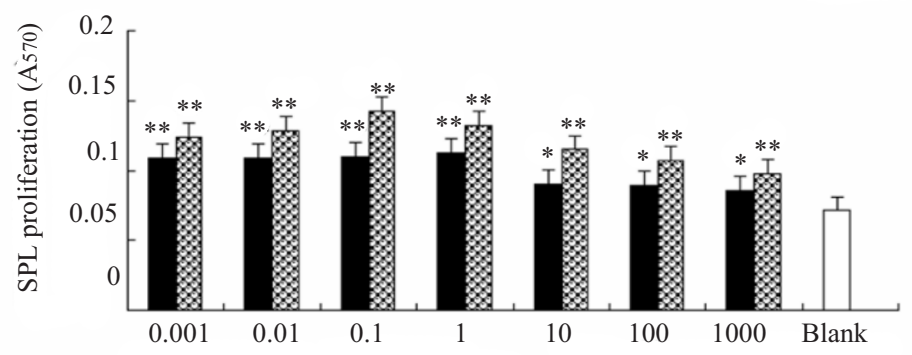

(D)

- NMS

$\mathrm{NMS}+\mathrm{PHA}$

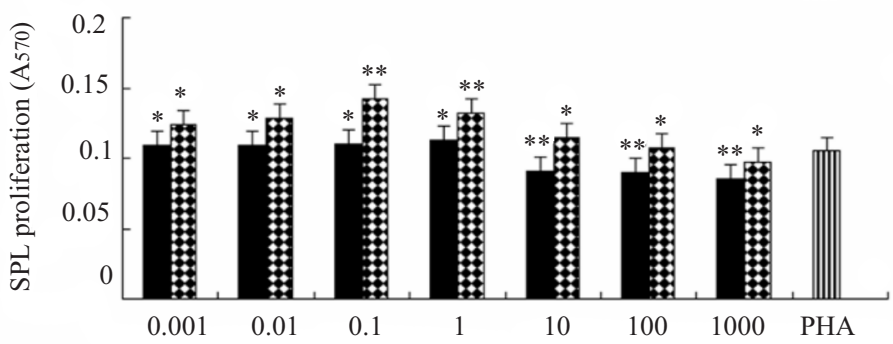

Fig. 4. Effect of NMS treatment on the proliferation of pig SPLs. A= NMS groups and NMS+ LPS groups compared with blank groups, $\mathrm{B}=\mathrm{NMS}$ groups and NMS +LPS groups compared with LPS groups, $\mathrm{C}=\mathrm{NMS}$ groups and NMS +PHA groups compared with blank groups, $\mathrm{D}=\mathrm{NMS}$ groups and NMS+PHA groups compared with PHA groups. SPLs, splenic lymphocytes; LPS, lipopolysaccharide; PHA, phytohemagglutinin. Statistical significance was set at $\mathrm{p}<0.05\left({ }^{*}\right)$ and $\mathrm{p}<0.01\left({ }^{* *}\right)$. 


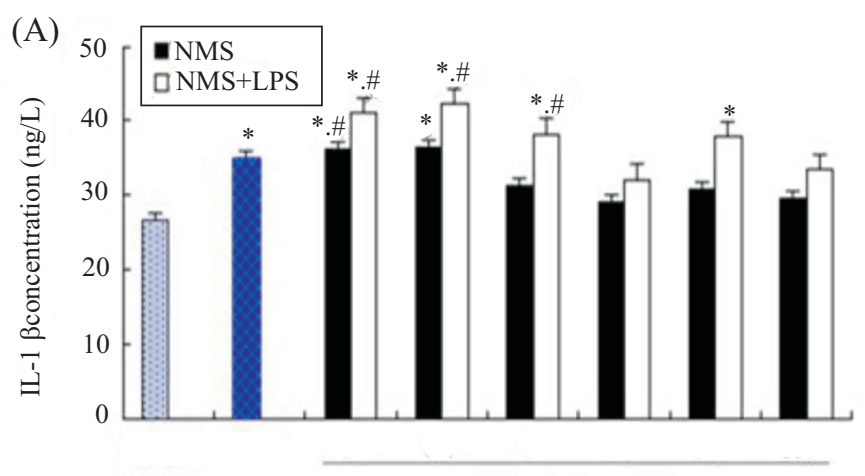

(B)
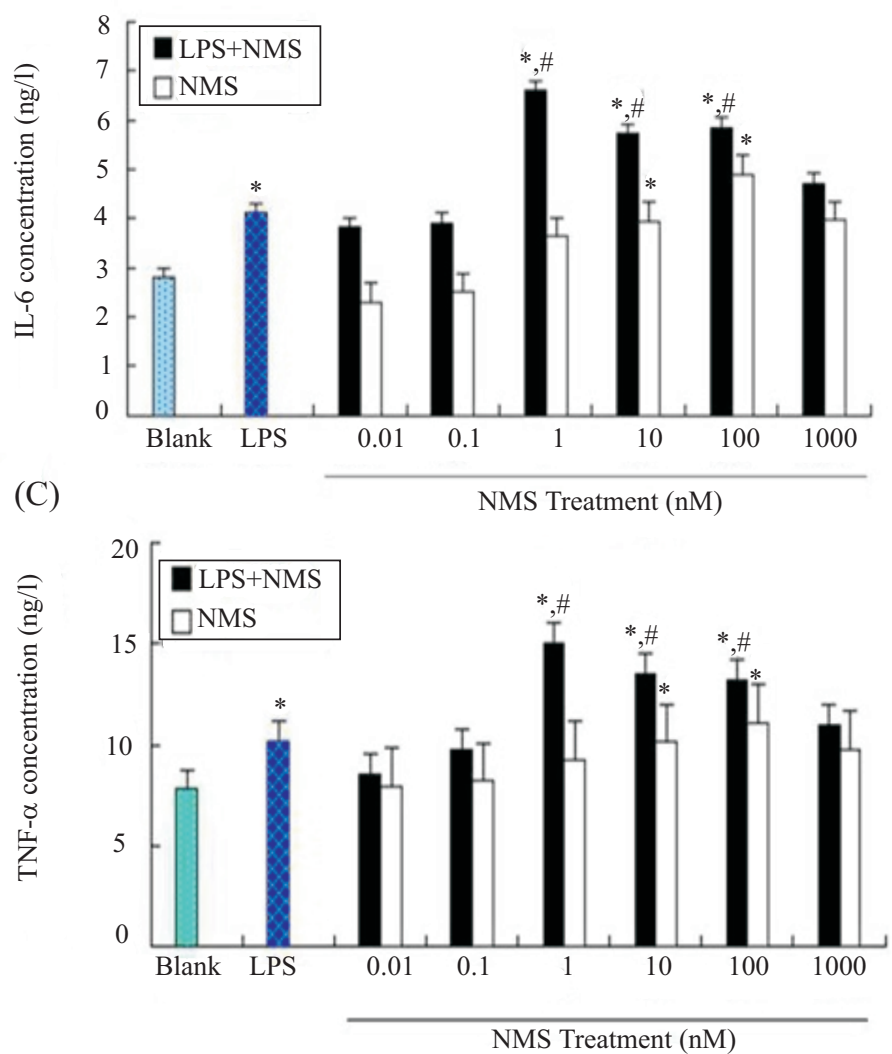

Fig. 5. Effect of NMS on IL-1 $\beta$ (A), IL-6 (B) and TNF- $\alpha$ (C) secretion of pig PAMs. PAMs, pulmonary alveolar macrophages; 0.01-1000 nM, the concentration of NMS; LPS, lipopolysaccharide. Statistical significance was set at $\mathrm{p}<0.05\left({ }^{*}\right.$, compared with blank groups) and $\mathrm{p}<0.05$ (\#, compared with LPS groups).

In summary, this paper for the first time reports the distribution and expression of NMU1R in pig SPLs and PAMs, and shows the effect of NMS in pig SPLs and PAMs. All the results obtained suggest that NMS is involved in SPL proliferation and the secretion of pro-inflammatory cytokines of PAMs. This is important to initially understand the effects of the cellular immune response to NMS on immune cells because NMS may act as an immunomodulatory factor that is activated by its receptor NMU1R.

\section{Acknowledgements}

This work was supported by the National Natural Science Foundation of China (31302050), research program sponsored by Ministry of Education of Fujian PR China (JK2013015) and Young Academic Rookie of Jinshan Scholar of Fujian Agriculture and Forestry University. 


\section{References}

Atsuchi K, Asakawa A, Ushikai M, Ataka K, Tanaka R, Kato I, Fujimiya M, Inui A (2010) Centrally Administered Neuromedin S Inhibits Feeding Behavior and Gastroduodenal Motility in Mice. Horm Metab Res 42(7): 535-538.

Fujii R, Hosoya M, Fukusumi S, Kawamata Y, Habata Y, Hinuma S, Onda $H$, Nishimura O, Fujino M (2000) Identification of neuromedin $\mathrm{U}$ as the cognate ligand of the orphan $G$ protein-coupled receptor FM-3. J Biol Chem 275(28): 21068-21074.

Hanada R, Nakazato M, Murakami N, Sakihara S, Yoshimatsu H, Toshinai K, Hanada T, Suda T, Kangawa $\mathrm{K}$, Matsukura S, Sakata T (2001) A role for neuromedin $\mathrm{U}$ in stress response. Biochem Biophys Res Commun 289(1): 225-228.

Hanada T, Date Y, Shimbara T, Sakihara S, Murakami N, Hayashi Y, Kanai Y, Suda T, Kangawa K, Nakazato $M$ (2003) Central actions of neuromedin $U$ via corticotropin- releasing hormone. Biochem Biophys Res Commun 311: 954-958.

Hedrick JA, Morse K, Shan L, Qiao X, Pang L, Wang S, Laz T, Gustafson EL, Bayne M, Monsma FJ Jr (2000) Identification of a human gastrointestinal tract and immune system receptor for the peptide neuromedin U. Mol Pharmacol 58: 870-875.

Howard AD, Wang R, Pong S, Mellin TN, Strack A, Guan XM, Zeng Z, Williams Jr, David L, Feighner SD, Nunes CN, Murphy B, Stair JN, Yu H, Jiang Q, Clements MK, Tan CP, McKee KK, Hreniuk DL, McDonald TP, Lynch KR, Evans JF, Austin CP, Caskey CT, Van der Ploeg L H, Liu Q (2000) Identification of receptors for neuromedin $U$ and its role in feeding. Nature 406(6791): 70-74.

Ida T, Mori K, Miyazato M, Egi Y, Abe S, Nakahara K, Nishihara M, Kangawa K, Murakami N (2005) Neuromedin S is a novel anorexigenic hormone. Endocrinology 146(10): 4217-4223.

Johnson EN, Appelbaum ER, Carptenter DC, Cox RF, Disa J, Foley JJ, Ghosh SK, Naselsky DP, Pullen MA, Sarau HM, Scheff SR, Steplewski KM, Zaks-Zilberman M, Aiyar N (2004) Neuromedin Elicits Cytokine Release in Murine Th2-Type T Cell Clone D10.G4.1. J Immunol 173(11): 7230-7238.

Kelley J (1990) Cytokines of the lung. Am Rev Respir Dis 141(3): 765-788.

Malendowicz LK, Ziolkowska A, Rucinski M (2012) Neuromedins $\mathrm{U}$ and $\mathrm{S}$ involvement in the regulation of the hypothalamo-pituitary-adrenal axis. Front Endocrinology 3: 156.

Mori K, Miyazato M, Ida T, Murakami N, Serino R, Ueta Y, Kojima M, Kangawa K (2005) Identification of neuromedin $\mathrm{S}$ and its possible role in the mammalian circadian oscillator system. EMBO J 24(2): 325-335.

Mori K, Miyazato M, Kangawa K (2008) Neuromedin S: discovery and functions. Results Probl Cell Differ 46: 201-212.

Moriyama M, Sato T, Inoue H, Fukuyama S, Teranishi H, Kangawa K, Kano T, Yoshimura A, Kojima M (2005) The neuropeptide neuromedin $\mathrm{U}$ promotes inflammation by direct activation of mast cells. J Exp Med 202(2): 217-224.

Moriyama M, Matsukawa A, Kudoh S, Takahashi T, Sato T,
Kano T, Yoshimura A, Kojima M (2006a) The neuropeptide neuromedin U promotes IL-6 production from macrophages and endotoxin shock. Biochem Biophys Res Commun 341(4): 1149-1154.

Moriyama M, Fukuyama S, Inoue H, Matsumoto T, Sato T, Tanaka K, Kinjyo I, Kano T, Yoshimura A, Kojima $M$ (2006b) The neuropeptide neuromedin $U$ activates eosinophils and is involved in allergen-induced eosinophilia. Am J Physiol Lung Cell Mol Physiol 290(5): L971-L977.

Nakazato M, Murakami N, Date Y, Mondal MS, Kojima MY, Kangawa K, Matsukura S, Hanada R (2000) Central effects of neuromedin $\mathrm{U}$ in the regulation of energy homeostasis. Biochem Biophys Res Commun 277(1): 191-194.

Nakahara K, Kojima M, Hanada R, Egi Y, Ida T, Miyazato M, Kangawa K, Murakami N (2004) Neuromedin U is involved in nociceptive reflexes and adaptation to environmental stimuli in mice. Biochem Biophys Res Commun 323(2): 615-620.

Peier A, Kosinski J, Coxyork K, Qian Y, Desai K, Feng Y, Trivedi P, Hastings N, Marsh D J (2009) The Antiobesity Effects of Centrally Administered Neuromedin U and Neuromedin S Are Mediated Predominantly by the Neuromedin U Receptor 2 (NMUR2). Endocrinology 150(7): 3101-3109.

Sakamoto T, Mori K, Nakahara K, Miyazato M, Kangawa K, Sameshima H, Murakami N (2007) Neuromedin S exerts an antidiuretic action in rats. Biochem Biophysi Res Commun 361(2): 457-461.

Shousha S, Nakahara K, Sato M, Mori K, Miyazato M, Kangawa K, Murakami N (2006) Effect of neuromedin S on feeding regulation in the Japanese quail. Neurosci Lett 391(3): 87-90.

Solis-Maldonado C, Quintanilla-Licea R, Tamez-Guerra R, Rodrtguez-Padilla C, Gomez- Flores R (2003) Differential effects of synthetic indoloquinolizines on in vitro rat lymphocyte and macrophage functions. Int Immunopharmacol 3(9): 1261-1271.

Vigo E, Roa J, López M, Castellano JM, Fernandez-Fernandez R, Navarro VM, Pineda R, Aguilar E, Dieguez C, Pinilla L, Tena-Sempere $M$ (2007) Neuromedin S as novel putative regulator of luteinizing hormone secretion. Endocrinology 148(2): 813-823.

Wang F, Zhang Y, Jiang X, Zhang Y, Zhang L, Gong S, Liu C, Zhou L, Tao J (2011) Neuromedin U inhibits T-type $\mathrm{Ca} 2+$ channel currents and decreases membrane excitability in small dorsal root ganglia neurons in mice. Cell Calcium 49(1): 12-22.

Yang G, Su J, Li X, Yao Y, Lei Z, Yang X, Kou R, Liu $Y$ (2009) Expression of NMS and NMU2R in the pig reproductive axis during the estrus cycle and the effect of NMS on the reproductive axis in vitro. Peptides 30(12): 2206-2212.

Yang G, Su J, Yao Y, Lei Z, Zhang G, Li X (2010) The regulatory mechanism of neuromedin $S$ on luteinizing hormone in pigs. Anim Reprod Sci 122(3-4): 367-374.

Yang G, Su J, Yao Y, Lei Z, Zhang G, Liu Y, Liu J, Li $X$ (2012) Distribution of neuromedin $S$ and its receptor NMU2R in pigs. Res Vet Sci 92(2): 180-186.

Yao Y, Su J, Yang G, Zhang G, Lei Z, Zhang F, Li X, Kou R, Liu Y, Liu J (2011) Effects of neuropeptide $S$ on the proliferation of splenic lymphocytes, phagocytosis, and proinflammatory cytokine production of pulmonary alveolar macrophages in the pig. Peptides 32(1): 118-124. 